\title{
An Assessment Capability for LNG Leaks in Complex Environments
}

\author{
Sydney D. Ryan, Robert C. Ripley \\ Lloyd's Register Applied Technology Group, Halifax, Canada \\ Email: Sydney.Ryan@lr.org
}

How to cite this paper: Ryan, S.D. and Ripley, R.C. (2018) An Assessment Capability for LNG Leaks in Complex Environments. Journal of Geoscience and Environment Protection, 6, 65-77. https://doi.org/10.4236/gep.2018.66005

Received: April 26, 2018

Accepted: June 19, 2018

Published: June 22, 2018

Copyright ( 92018 by authors and Scientific Research Publishing Inc. This work is licensed under the Creative Commons Attribution International License (CC BY 4.0).

http://creativecommons.org/licenses/by/4.0/

(c) (i) Open Access

\begin{abstract}
Pollutants may be introduced into urban or marine settings by various means and could result in an adverse impact to public safety and the environment. Therefore, it is important for emergency management personnel to understand the potential risks and physical extents of a leaked substance, whether it is toxic, flammable or explosive. Traditional tools for predicting the atmospheric dispersion of leaked substances are quick and simple to use, but may not adequately consider the effects of the built environment that includes complex urban and terrain geometries. Alternatively, CFD methods have been increasing in application; although, their superior accuracy is met with commensurate manual effort. The All Hazards Planner is a fast, accurate gas dispersion modelling tool for city and port environments, which employs a full-physics CFD approach but automates the intensive manual effort. In this work, a credible LNG leak from a 12-mm-diameter hole is modelled for two hypothetical case studies: adjacent to an LNG tanker and between a cruise ship and pier during bunkering. The LNG vapour flammability extents are compared to an empirical model in the absence of geometry effects and are contrasted with geometry effects to highlight the importance of the real environment. The free-field extents are invariant, whereas the inclusion of geometry is shown to reduce the flammability extents by spreading at the ground-level and forcing the plume upwards.
\end{abstract}

\section{Keywords}

All Hazards Planner, Atmospheric Gas Dispersion, Computational Fluid Dynamics, Urban Canopy Flow, Emergency Response, Geohazards, Health and Safety, Environmental Impact

\section{Introduction}

Predicting the dispersion of gas can be quite challenging in complex environ- 
ments due to the interaction between the atmospheric flow conditions and the local flow features amongst buildings, vessels and terrain. Traditional modeling has used operational methods which are typically derived from the integral nature of atmospheric dispersion [1] [2]. These methods are generally based on Gaussian dispersion models and are often referred to as "fast response models". Like their name suggests, these approaches are quick and can produce solutions for multiple scenarios in a short time. They are frequently modified for more general purposes and may include complicated dispersion processes such as atmospheric stratification, buoyancy, chemistry, pooling and deposition. Some modifications may even include simple approaches to account for building effects [3] [4]. However, it is important to note that many fast response methods are not able to treat complex geometries explicitly with detail, and it is therefore important to understand the fundamental limitations of these models.

Computational Fluid Dynamics (CFD) has largely emerged as a popular tool for dispersion analysis in urban areas over the past two decades due to its ability to consider complex geometry effects. In CFD, some form of the Navier-Stokes equations is solved which is generally coupled with advection/diffusion transport equations for turbulence properties and gas species. Although physics-based methods are more time-consuming than empirical modelling approaches, CFD provides greater detail and accuracy of the flow field and plume. Recently, CFD has been used extensively to assess pollutant dispersion around buildings. Many of these studies focus on the near-field phenomena and are summarized in [5]. Additional CFD studies investigate gas dispersion over large areas of real urban environments [6] [7]. In particular, [6] highlights the differences between CFD and more traditional integral methods.

The All Hazards technology (Lloyd's Register) is a fast predictive tool for emergency planning, preparedness and response with application to extreme hazardous incidents and industrial accidents near urban areas. All Hazards uses CFD in real-world environments to provide risk assessment and environmental impact prediction for accidents and technical failures in cities, ports, and industrial facilities near populated areas. Although All Hazards employs a formal CFD approach, the traditional complexities associated with CFD (such as geometry generation, mesh creation, boundary conditions and flow specifications) are automatically performed. As such, the tool maintains accuracy while simplifying usability, thereby allowing less specialized users to take advantage of its potential. Further, All Hazards has an embedded online virtual globe interface that provides interactive visual display in a mapping-based environment; the use of Geographic Information System (GIS) coordinates facilitates geo-located 3D geometry creation and sharing of results.

This paper demonstrates the importance of the local environment on gas dispersion. Results for free-field dispersion are first compared against predictions using a traditional modeling approach, and later contrasted with results considering congested urban and marine environments. 


\section{All Hazards Planner for Gas Dispersion}

The All Hazards Planner is a fast predictive tool for the accurate assessment atmospheric dispersion by employing a full-physics CFD approach using a built-in low-speed solver [8]. All Hazards uses an implicit, time-accurate CFD code and uses a finite volume discretization method on structured Cartesian grids. All Hazards solves the full Reynolds-Averaged Navier-Stokes (RANS) equations allowing for variations in fluid density due to local changes in pressure, temperature, humidity and gas concentration [9]. The Reynolds stresses in the RANS equations are approximated using the standard $k-\varepsilon$ turbulence model [10] with standard wall functions. The transported turbulent kinetic energy $(k)$ and turbulent eddy dissipation $(\varepsilon)$ quantities are used to define a turbulent eddy viscosity which increases the effective diffusion rate of momentum, energy and species concentrations in the flow field. All Hazards applies the following set of boundary conditions on wall surfaces to satisfy logarithmic wall laws [11]:

$$
\tau_{w}=-\rho u_{\tau}^{2}, k=\frac{u_{\tau}^{2}}{\sqrt{C_{\mu}}}, \varepsilon=\frac{u_{\tau}^{3}}{\kappa y}
$$

where $\tau_{w}$ is the viscous shear stress, $\rho$ is the air density, $y$ is the normal distance from the wall, $C_{\mu}=0.09, \kappa=0.41$, and $u_{\tau}$ is the friction velocity which satisfies the log-law:

$$
\frac{u}{u_{\tau}}=\frac{1}{\kappa} \ln \left(y^{+}\right)+B
$$

where $u$ and $y^{+}$are the tangential velocity and normalized distance from the wall. The variable, $B$, is defined by the following equation for rough surfaces [12]:

$$
\begin{gathered}
B=8.0-\frac{1}{\kappa} \ln \left(z_{0}^{+}\right) \\
z_{0}^{+}=\frac{u_{\tau} z_{0}}{v}, y^{+}=\frac{u_{\tau} y}{v}
\end{gathered}
$$

where $v$ is the kinematic viscosity and $z_{0}$ is the terrain surface roughness length. A constant value of $B$ equal to 5.0 is traditionally assumed for smooth surfaces [12], however proper treatment of the boundary layer includes the effect of surface roughness length at local positions. These conditions imply the following boundary values of turbulent eddy viscosity, $v_{T}$, and the production of turbulent kinetic energy, $P_{k}$, which is assumed to be in equilibrium with dissipation.

$$
v_{T}=u_{\tau} \kappa y, P_{k}=\frac{u_{\tau}^{3}}{\kappa y}
$$

The creation of a computational mesh for use in CFD simulation of complex urban environments can be quite challenging. In general, this process accounts for a substantial portion of CFD studies and requires a certain degree of mesh 
generation expertise. The All Hazards tool avoids this effort by taking advantage of a structured Cartesian grid with anisotropic mesh refinement and an immersed boundary methodology [8]. In this method, the urban geometry (terrain and structures) is overlaid on the structured grid which automatically detects and refines the mesh in the normal direction around the surfaces. The automatic refinement enhances accuracy near buildings where flow gradients are large and better captures the Urban Boundary Layer (UBL) development.

All Hazards uses GIS-based geometry which facilitates model file and results sharing. The embedded virtual globe environment is based on an open source platform from Cesium, allowing interactive visual display of 3D data on a mapping-based environment. The local environment terrain and building geometry is automatically generated using open source libraries which store widely available GIS information, as shown in Figure 1. In this example, a digital elevation model [13] is employed in combination with a 3D building shape file [14], with vertical position defined above sea level (ASL). To increase the accuracy of the UBL development and flow features, specified GIS-based patches are used to define surface temperature $(T)$ and roughness $\left(z_{0}\right)$ on the terrain regions. Figure 1 also shows how these are applied in GIS coordinates to alter the surface properties of urban areas (yellow, orange), forests (blue, green) and bodies of water (default).

An All Hazards simulation involves two sequential CFD steps. A steady-state solution to the urban canopy aerodynamic flow is first calculated using an implicit incompressible flow technique, followed by a time-marching solution to the transient buoyant gas dispersion [8]. Optionally, All Hazards uses a wind field library system to store pre-converged urban wind fields. This technique accelerates the full scenario modeling effort allowing users to compute leak scenarios in near-real time; that is, simulation of a 10-minute-duration leak requires about 10 minutes of wall time on a typical computer workstation. All

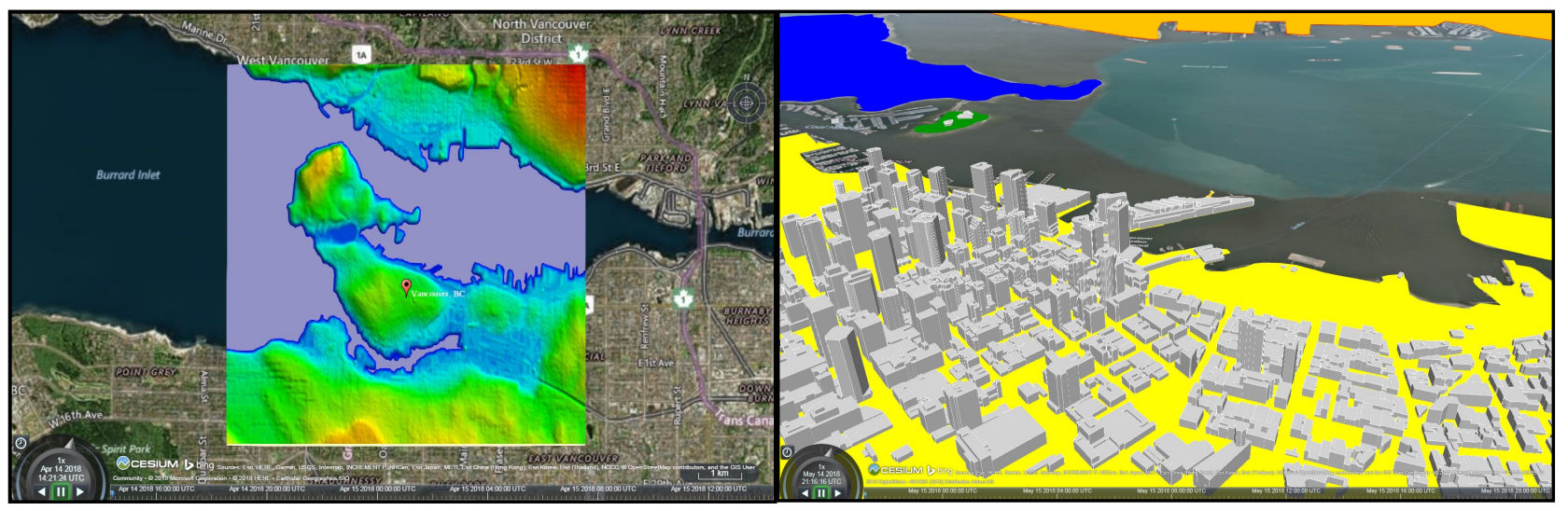

Figure 1. Virtual globe interface highlighting local environmental data: terrain data from Natural Resources Canada [13] (elevation from blue $=0 \mathrm{~m}$ ASL to red $=185 \mathrm{~m} \mathrm{ASL}$ ) (left); and building shape data from Vancouver Open Data [14] (right). GIS-based terrain patches used to specify surface information are visualized on the right: yellow/orange-ashfault/concrete/obstacles with $z_{0}=0.25 \mathrm{~m}, T=15^{\circ} \mathrm{C}$; blue/green-forest with $z_{0}=0.5 \mathrm{~m}, T=15^{\circ} \mathrm{C}$; default-open water with $z_{0}=0.001 \mathrm{~m}, T=10^{\circ} \mathrm{C}$. 
Hazards further takes advantage of its structured grid arrangement applying a novel and robust multigrid technique to accelerate solution convergence times [8].

\section{Free-Field Validation}

Besides bulk transport for energy, Liquefied Natural Gas (LNG) as fuel for ships has steadily increased in practice over the past decade, and therefore bunkering is necessitated in city ports. In order to ensure the safety of ship occupants and nearby personnel, it is important to fully understand the outcomes of particular, and credible, leak scenarios. This way, adequate bunkering exclusion zones may be applied during fueling in order to ensure potential sources of ignition remain outside the extent of flammability limits for any leaked gas.

For example, a credible leak scenario for bunkering is a continuous leak from a 12-mm-diameter hole in a fuel line with a system pressure of 8 barg [15]. The system pressure and hole size can be used to calculate a leak rate, in terms of exit velocity, $V_{e}=59.6 \mathrm{~m} / \mathrm{s}$ and mass flow, $\dot{m}=3.03 \mathrm{~kg} / \mathrm{s}$ using Equations ((6) and (7)).

$$
\begin{gathered}
\Delta P=0.5 \rho V_{e}^{2} C_{D} \\
\dot{m}=\rho A V_{e}
\end{gathered}
$$

$\Delta P$ is the system (gauge) pressure, $\rho$ is the LNG liquid density $\left(450 \mathrm{~kg} / \mathrm{m}^{3}\right)$ at a temperature of $-162^{\circ} \mathrm{C}$, and $A$ is the area of the hole. To model the worst-case scenario, it is assumed that the discharge coefficient, $C_{D}$, is equal to 1.0 , and the LNG vaporizes instantaneously upon release. As is customarily done, the gas is assumed to be pure methane $\left(\mathrm{CH}_{4}\right)$. The leak is assumed to occur at a $1 \mathrm{~m}$ elevation ASL for a duration of $300 \mathrm{~s}$.

Historical Vancouver climate data [16] was used to determine a likely wind speed of $12 \mathrm{~km} / \mathrm{hr}$ and direction from the East. A neutral Pasquill stability class (type D) was used, and it was assumed that the ambient air temperature and relative humidity were $15^{\circ} \mathrm{C}$ and $50 \%$, respectively.

Using traditional Gaussian dispersion models, such as DNV-GL PHAST, the details of the terrain and physical structures (i.e., buildings and vessels) are not considered, and the direction of the wind is unimportant. Figure 2 shows the PHAST prediction of horizontal plume extents in terms of its Lower Flammability Limit (LFL) of 44,000 ppm. The LFL of the plume extends $43 \mathrm{~m}$ downwind, whereas as the maximum distance reached by half of its LFL is $70 \mathrm{~m}$.

The PHAST plume extent predictions were used to cross-validate All Hazards for free-field dispersion in the absence of urban geometry effects. Table 1 compares the horizontal extent, width and vertical extent of the LFL and 1/2 LFL ( $4.4 \%$ and $2.2 \%$ by volume, respectively). The three-dimensional LNG extents compare well between PHAST and All Hazards for free-field dispersion. Further LNG dispersion validation studies have been completed following the procedure established by the Pipeline and Hazardous Materials Safety Administration 


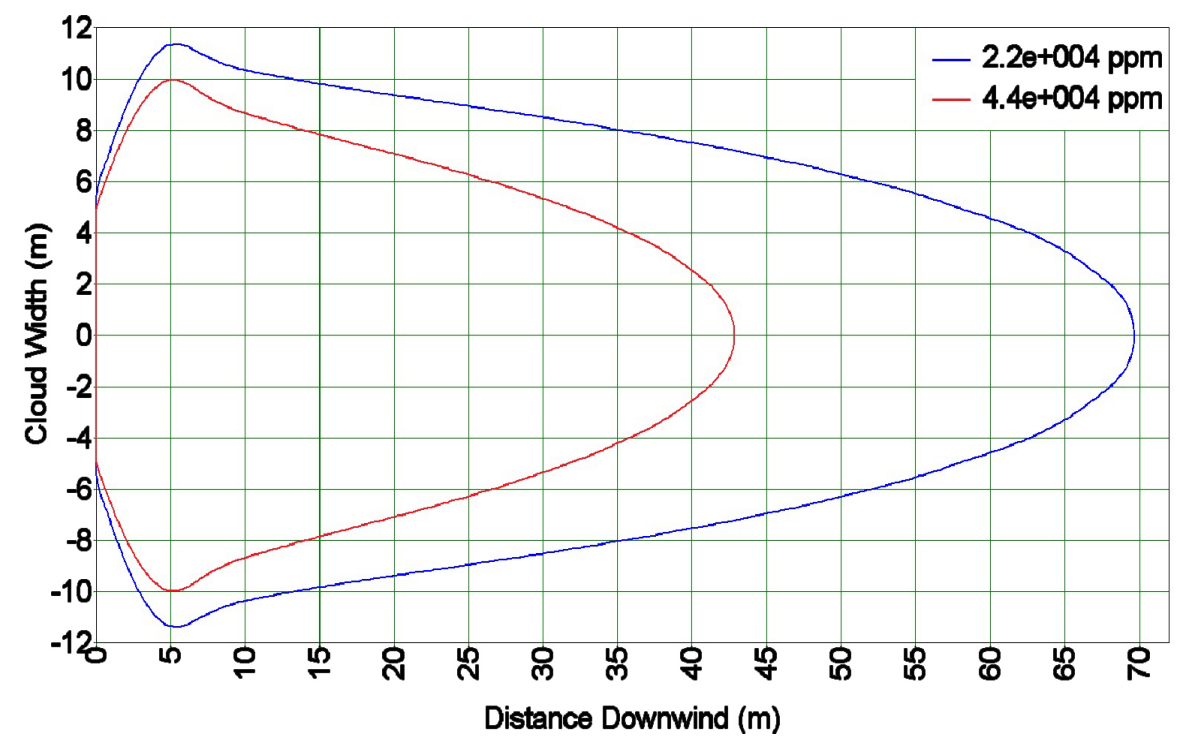

Figure 2. Horizontal extent of LNG lower flamability limit as predicted by PHAST. This result comes directly from the empirical model as maximum concentration contours at ground level.

Table 1. Free-field comparsion of LNG horizontal extent, width, and vertical extent for PHAST and All Hazards.

\begin{tabular}{ccccc}
\hline & & Horizontal Extent (m) & Width (m) & Vertical Extent (m) \\
\hline PHAST & LFL (1/2 LFL) & $43(70)$ & $20(22)$ & $1.9(3)$ \\
All Hazards (Free-Field) & LFL (1/2 LFL) & $46(78)$ & $16(20)$ & $2(3)$ \\
Percent Difference (\%) & LFL (1/2 LFL) & $7.0(11)$ & $20(10)$ & $5.3(0)$ \\
\hline
\end{tabular}

(PHMSA) of the USA Department of Transportation (DOT), the National Fire Protection Association (NFPA), and the Federal Energy Regulatory Commission (FERC) [17]. The extensive list of validation studies required for PHMSA certification includes free-field dispersion, obstructed dispersion (e.g., fences, dykes), sloped terrains, and wind tunnel tests-all with experimental benchmark data for comparison. Model evaluation employs several statistical quantities for comparing observed and predicted gas concentrations over an array of downwind measuring locations. Each statistical measure has an accepted value as defined by Hanna et al. [18]; however, the most robust measure typically limits the deviation to $50 \%$ of predicted concentrations within a factor of two [17] [18].

\section{Semi-Confined and Obstructed Gas Dispersion}

To demonstrate the capability of All Hazards Planner and to highlight the importance of considering terrain and obstacle geometries, the above-described leak is simulated in two separate hypothetical, yet realistic, scenarios: 1) an LNG tanker ship entering the Vancouver (Canada) Harbour near Lion's Gate Bridge; and, 2) during bunkering for a cruise ship docked at Vancouver Port near Canada Place. Although possible, these scenarios are not based on specific historic 
occurrences and are for demonstration purposes only.

For each scenario, the same credible leak described in Section 3 occurred at a $1 \mathrm{~m}$ height above the water surface adjacent to the vessel hull (i.e., tanker and cruise ship) for a duration of $300 \mathrm{~s}$. The same atmospheric wind conditions were used for both examples, while the wind direction was altered for the cruise ship scenario to analyse an increased risk of LNG vapour reaching heavily populated areas and transportation routes.

\subsection{LNG Tanker Scenario}

An LNG tanker is entering Vancouver Harbour at $49^{\circ} 18^{\prime} 50.2456^{\prime \prime} \mathrm{N}$ and $123^{\circ} 7^{\prime} 47.3974 " \mathrm{~W}$, approximately $600 \mathrm{~m}$ from the Lion's Gate Bridge, when a mechanical failure causes the ship to leak LNG. The ship is traveling in a south-east direction, and the leak occurs on the east (upwind) side of the ship. Figure 3 shows the All Hazards predictions of gas concentration on the terrain. To highlight the importance of the ship structure and terrain features on the dispersion, the All Hazards free-field results are also included in the figure.

Figure 3 shows significant differences in the gas plume when environment geometries are considered. Compared with the free-field dispersion, far downstream the plume is accelerated around the elevated arboreal terrain causing gas to spread farther transverse to the wind direction. Although the concentration levels are well below the flammability limits for this particular fuel and scenario, the visual impact of the plume approaching the Lion's Gate Bridge, highlights the importance for emergency personnel to have an accurate representation of the leak extent. Near the vessel, the plume path is obstructed and forced around the ship hull. This phenomenon acts to reduce the horizontal LFL extents to 26 $\mathrm{m}$ (43 $\mathrm{m}$ for $1 / 2 \mathrm{LFL})$ and widen the footprint to $28 \mathrm{~m}$ (34 $\mathrm{m}$ for $1 / 2 \mathrm{LFL})$; thus, restricting the flammability zone to the upwind side of the tanker. Because confinement effects are small in this example, the vertical LNG vapour extents are unchanged as the plume accelerates around the ship hull. A larger leak, or more confined leak (i.e., a leak closer to the hull, or the ship traveling perpendicular to the wind), may result in concentration levels exceeding the LFL on the tanker topside. Figure 4 shows the LNG vapour concentration contour on the tanker surface and a three-dimensional $10 \mathrm{ppm}$ iso-surface at $60 \mathrm{~s}$ after the leak initiates. All Hazard's automatic generation of these three and four-dimensional leak representations give a time-accurate visualization of the plume history facilitating crucial decision making and emergency response planning.

\subsection{Cruise Ship LNG Bunkering Scenario}

A cruise ship is docked at the Vancouver Port near Canada Place when a mechanical failure, or bunkering incident, results in an LNG leak. The vessel is docked on the north-west side of the pier, and the leak occurs in the space between the ship and pier. Figure 5 shows the All Hazards predictions of gas concentration on the ground with and without the inclusion of urban geometry and 


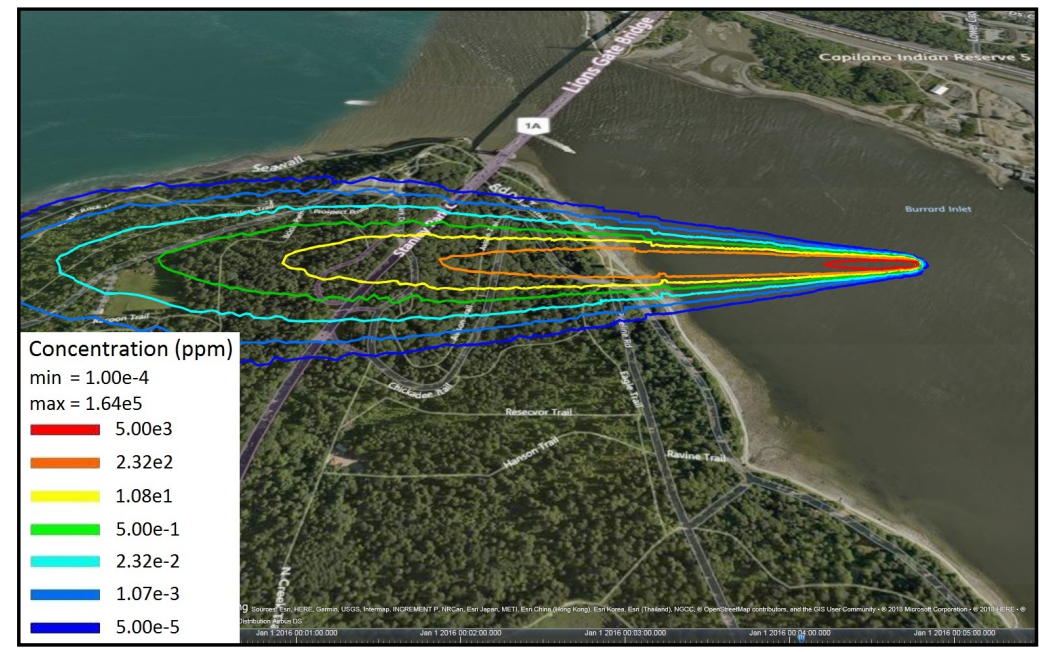

(a)

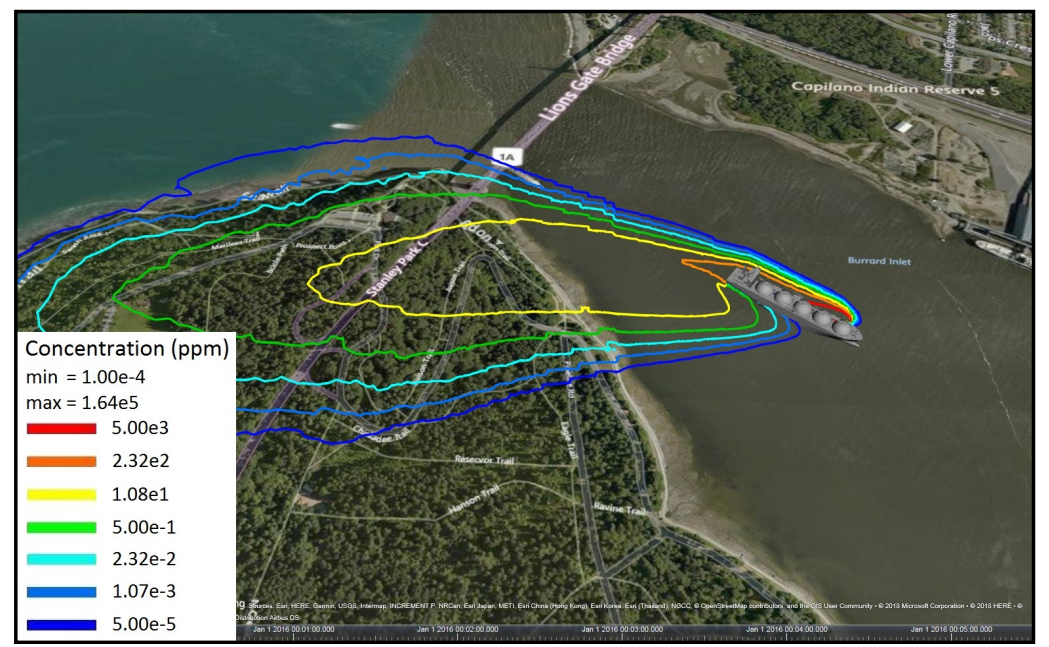

(b)

Figure 3. LNG concentration contour lines plotted along the ground without (a) and with (b) the inclusion of terrain and tanker geometry effects at $300 \mathrm{~s}$ following initial release.

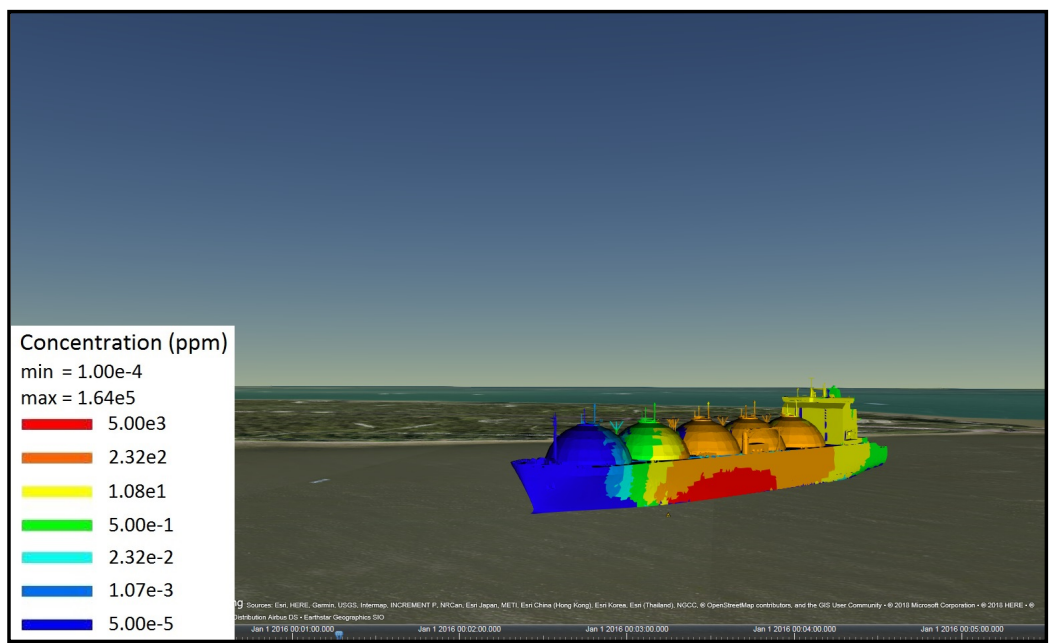

(a) 


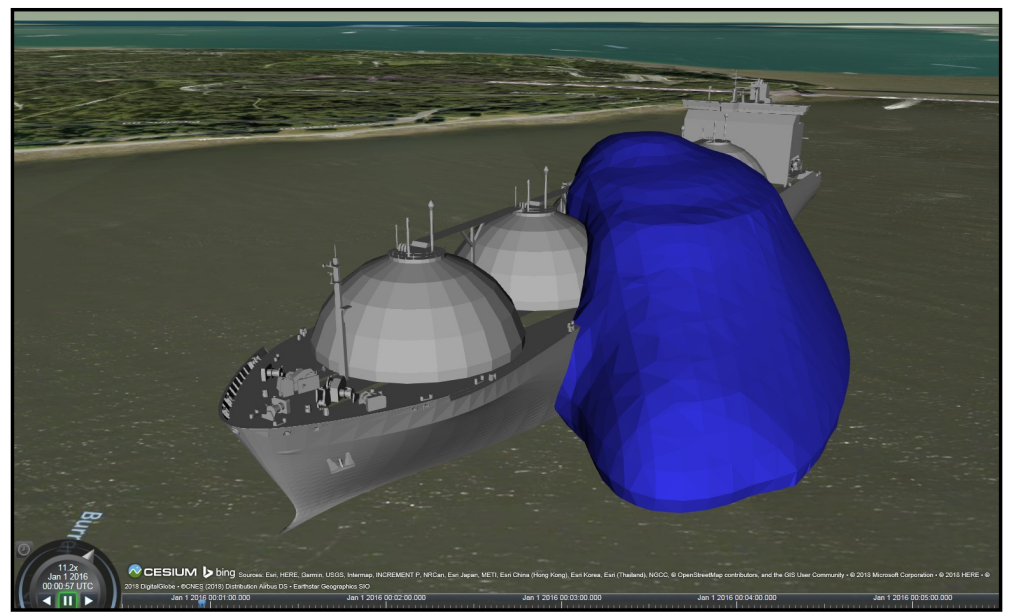

(b)

Figure 4. Three-dimensional visualization of LNG concentration: colour contour on the tanker ship surface (a) and iso-surface of $10 \mathrm{ppm}$ methane in air (b). Both results plotted at $60 \mathrm{~s}$.

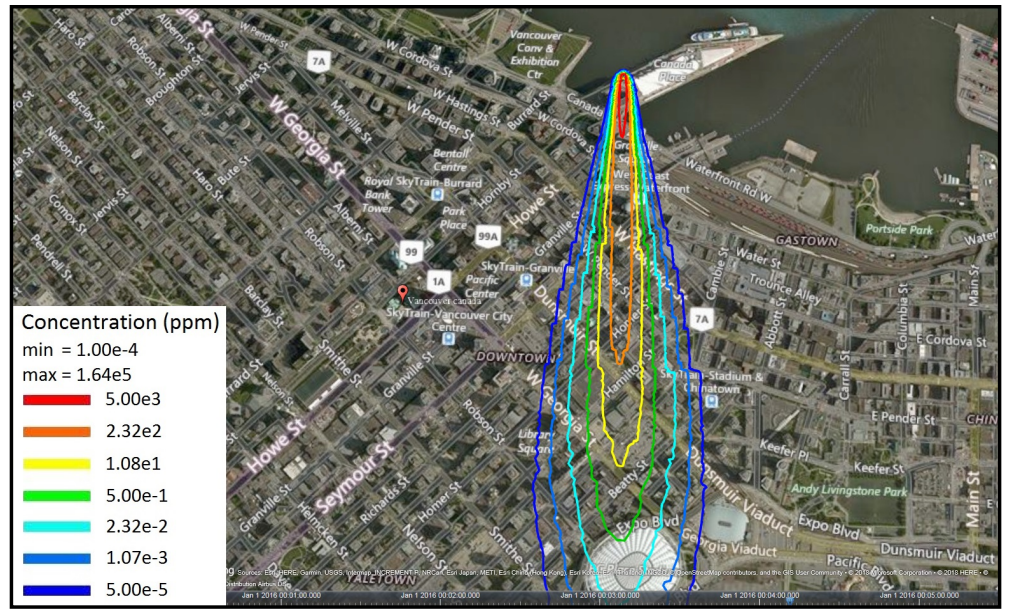

(a)

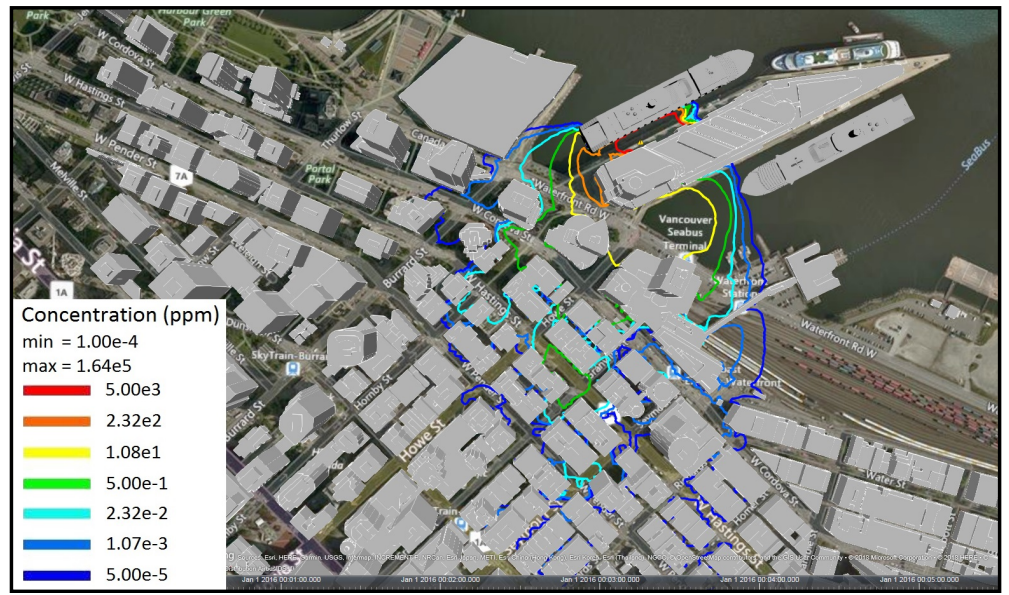

(b)

Figure 5. Ground-level LNG concentration contour lines without (a) and with (b) the inclusion of terrain, cruise ship and building geometry effects at $300 \mathrm{~s}$ following initial release. 
terrain effects, which are remarkably different.

Apart from direction, the free-field results are identical to the previous scenario and the validation case. However, complex port geometry greatly affects the plume evolution and extents. The LNG is leaked into a region between the ship and pier where the low wind speed causes the plume to spread very slowly and significantly affects the dispersion. The width of the LFL (and 1/2 LFL) extent is increased but remains confined within the gap between the ship hull and Canada Place. The horizontal LFL extent is reduced to $36 \mathrm{~m}$ (64 $\mathrm{m}$ for $1 / 2 \mathrm{LFL}$ ) and is not in the direction of the wind $\left(0^{\circ}\right)$. Instead, the dispersion extends partially upwind $\left(210^{\circ}\right)$ between the ship hull and pier. The large degree of confinement in this scenario significantly increases the vertical LFL extent to $5 \mathrm{~m}$ (11 $\mathrm{m}$ for $1 / 2 \mathrm{LFL}$ ) passing the open lifeboat space, and almost reaching the cruise ship upper deck.

Figure 6 shows a three-dimensional $1 \mathrm{ppm}$ iso-surface at $120 \mathrm{~s}$ and $240 \mathrm{~s}$ after

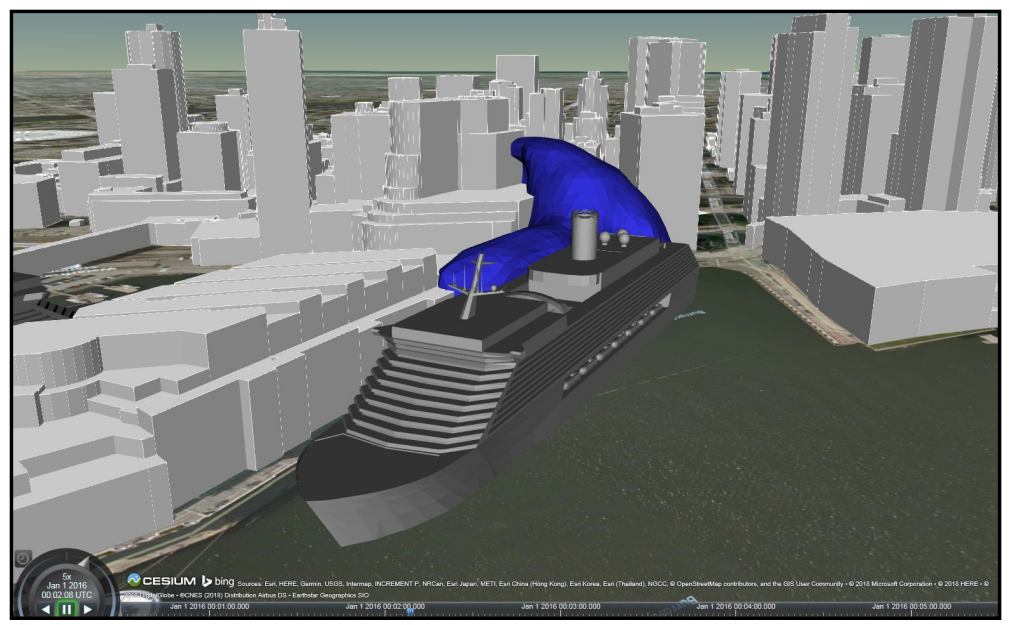

(a)

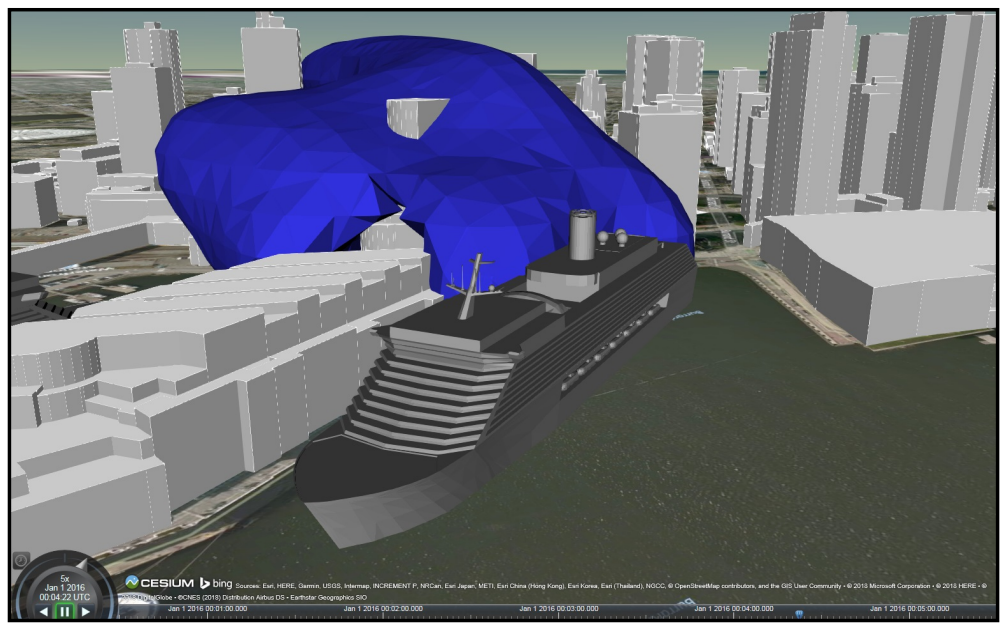

(b)

Figure 6. Three-dimensional 1 ppm LNG iso-surface at $120 \mathrm{~s} \mathrm{(a)} \mathrm{and} 240 \mathrm{~s}$ (b) after initial release. 
initial release. Due to the slow moving air, the plume is physically contained within the space between the ship and pier for roughly $120 \mathrm{~s}$ and reaches the urban canopy by $240 \mathrm{~s}$. After spreading outside this region, the plume becomes entrained in a north wind updraft caused by the flow around the downtown buildings, and is accelerated upwards engulfing the upper urban canopy. This results in a reduction of overall LNG concentrations reaching downtown, populated areas at street-level; although, ingestion of vapours by rooftop air intakes may be a concern.

The stagnation region between the ship and pier, the urban updraft, and other geometry effects act together to change the path of the LNG vapour plume. Figure 7 shows the time histories of LNG concentration at three locations (marked as white squares in Figure 5): entrance to the pier on the ship side, intersection of Waterfront Rd. and Howe St. (opposite side of pier), and intersection of W. Cordova St. and Granville St. These locations were down selected from an array of 12 monitor locations (specified in All Hazards) as they highlight deviations between free-field and obstructed dispersion. With the partially confined and obstructed environment, the concentration at the beginning of the pier reaches $650 \mathrm{ppm}$, while it is virtually undetected by the free-field analysis at the same position. Without the complex urban geometry, the concentration is over predicted at the first street intersection but under predicted at the second intersection by an order of magnitude. Further, the arrival time of the gas plume is greatly under predicted at both intersections when the geometry is not included. The magnitude of the gas concentration measurements may seem very small; however, levels of $10^{-3} \mathrm{ppm}$ have accurately been validated in [8] relative to city-scale dispersion experiments. The level of accuracy and detail provided by All Hazards CFD approach gives a clearer understanding of potential risks associated with the dispersal of a leaked substance.

\section{Conclusions}

The All Hazards Planner employs a full-physics CFD approach to modelling gas
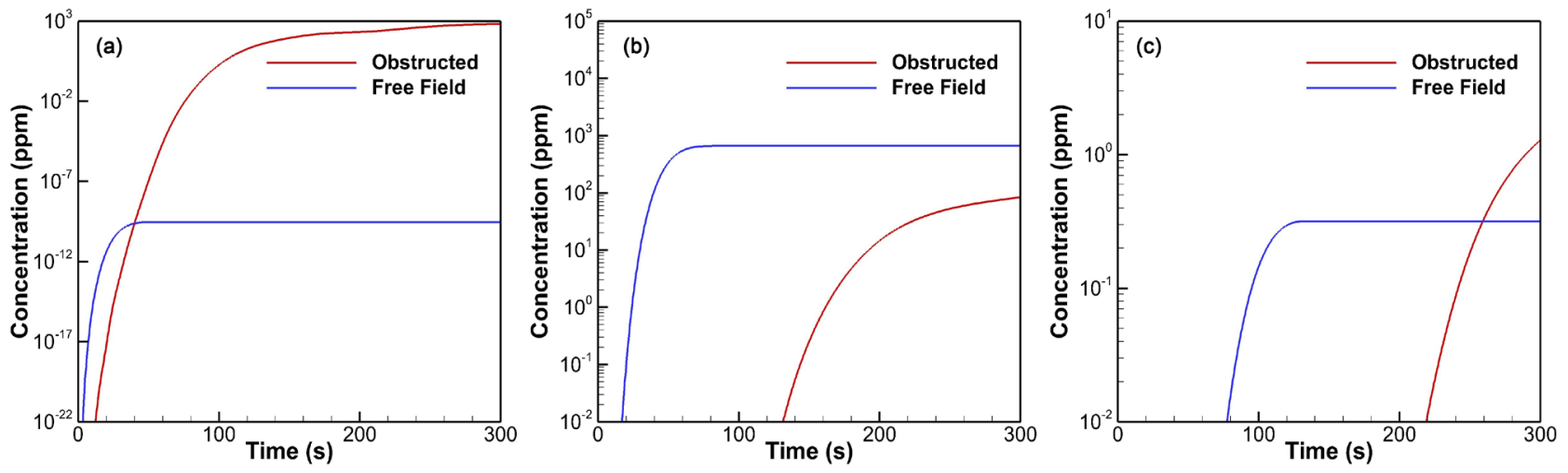

Figure 7. Time records of LNG vapour concentration at three locations: entrance to pier on the ship side (a), intersection of Waterfront Rd. and Howe St. (b), and intersection of W. Cordova St. and Granville St (c). 
dispersion in complex urban environments; however, the traditional complexities of CFD (i.e., geometry creation, meshing, and scientific visualization) are automated for the user.

A free-field study showed a good comparison between the predictions of LNG vapour cloud extents between All Hazards and empirical methods in the absence of building and terrain geometries. A more complete LNG dispersion validation study has been completed following certification guidelines of the Pipeline and Hazardous Materials Safety Administration.

Including the effects of built environments and vessels as aerodynamic obstacles has shown that free-field extents may be overly conservative. The interaction between the atmospheric boundary layer and complex urban terrain and geometries leads to non-Gaussian dispersion. These effects typically force the cloud to spread outwards and upwards reducing the horizontal extent of flammability limits at ground level. As such, some empirical models may estimate dispersion extents that could be too large. On the other hand, the vertical extents are often increased leading to concerns of gas vapours reaching the topsides of ships or air intakes on buildings or vessels.

Therefore, current industry-accepted bunkering exclusion zones and transportation safety templates should be revisited on a case-by-case basis, which may benefit from increased efficiency and lower operating costs afforded by more realistic dispersion predictions. The increased accuracy of All Hazards will provide a more complete understanding for assessing gas dispersion hazards and developing operational procedures.

\section{References}

[1] Stern, A.C. (1976) Air Pollution, Vol. III: Measuring, Monitoring, and Surveillance of Air Pollution. 3rd Edition, Academic Press, New York.

[2] Pasquill, F. and Smith, F. (1983) Atmospheric Diffusion. Horwood, Chichester.

[3] Carruthers, D.J., Holroyd, R.J., Hunt, J.C.R., Weng, W.S., Robins, A.G., Apsley, D.D., et al. (1994) UK-ADMS: A New Approach to Modelling Dispersion in the Earth's Atmospheric Boundary Layer. Journal of Wind Engineering and Industrial Aerodynamics, Elsevier, 52, 139-153. https://doi.org/10.1016/0167-6105(94)90044-2

[4] Robins, A., Carruthers, D. and McHugh, C. (1997) The ADMS Building Effects Module. International Journal of Environment and Pollution, Inderscience Publishers, 8, 708-717.

[5] Tominaga, Y. and Stathopoulos, T. (2013) CFD Simulation of Near-Field Pollutant Dispersion in the Urban Environment: A Review of Current Modeling Techniques. Atmospheric Environment, Elsevier, 79, 716-730. https://doi.org/10.1016/j.atmosenv.2013.07.028

[6] Labovsky, J. and Jelemensky, L. (2013) CFD-Based Atmospheric Dispersion Modeling in Real Urban Environments. Chemical Papers, Springer. 67, 1495-1503. https://doi.org/10.2478/s11696-013-0388-7

[7] Flaherty, J.E., Lamb, B., Allwine, K.J. and Allwine, E. (2007) Vertical Tracer Concentration Profiles Measured during the Joint Urban 2003 Dispersion Study. Journal of Applied Meteorology and Climatology, 46, 2019-2037. 
https://doi.org/10.1175/2006JAMC1305.1

[8] Ryan, S.D. and Ripley, R.C. (2018) A Geometric Multigrid Method with Immersed Boundaries for Simulating Atmospheric Dispersion in Complex Urban Environments. Accepted for the Proceedings of the 7 th International Symposium on Computational Wind Engineering.

[9] Ferziger, J.H. and Perić, M. (2002) Computational Methods for Fluid Dynamics. 3rd Edition, Springer-Verlag, Berlin Heidelberg. https://doi.org/10.1007/978-3-642-56026-2

[10] Launder, B.E. and Spalding, D.B. (1972) Lectures in Mathematical Models of Turbulence. Academic Press, London-New York.

[11] Grotjans, H. and Menter, F. (1998) Wall Functions for General Application CFD Codes. Proceedings of the 4th European Computational Fluid Dynamics Conference, John Wiley \& Sons, Chichester, 1112-1117.

[12] Schlichting, H. (1987) Boundary-Layer Theory. 7th Edition, McGraw-Hill, New York.

[13] National Resources Canada (2015) Free Data - Geogratis. http://www.nrcan.gc.ca/earth-sciences/geography/topographic-information/free-da ta-geogratis/11042

[14] City of Vancouver (2015) Open Data Catalogue. http://vancouver.ca/your-government/open-data-catalogue.aspx

[15] Stoffen, G. (2005) Guideline for Quantitative Risk Assessment "Purple Book" CPR 18E. Publication Series on Dangerous Substances, Volume 3. Ministry of Housing, Spatial Planning and the Environment, Netherlands.

[16] Environment and Climate Change Canada (2018) Metrics for Vancouver. https://vancouver.weatherstats.ca/metrics

[17] Ivings, M.J., Jagger, S.F., Lea, C.J. and Webber, D.M. (2007) Evaluating Vapor Dispersion Models for Safety Analysis of LNG Facilities. The Fire Protection Research Foundation, USA.

[18] Hanna, S.R., Hansen, O.R. and Dharmavaram, S. (2004) FLACS CFD Air Quality Model Performance Evaluation with Kit Fox, MUST, Prairie Grass, and EMU Observations. Atmospheric Environment, Elsevier, 38, 4675-4687.

https://doi.org/10.1016/j.atmosenv.2004.05.041 